\title{
A MORTE DIGNA COMO DIREITO FUNDAMENTAL
}

\author{
Carolina Bombonatto Borchart ${ }^{1}$ \\ Amanda Juncal Prudente ${ }^{2}$
}

\begin{abstract}
Resumo: O tema matriz do presente estudo aborda questões relativas à necessidade de se preservar a dignidade do homem na terminalidade da vida. Busca-se apresentar breves reflexões acerca do direito de se ter uma morte digna, sob o fundamento da autonomia da vontade como vertente do princípio da dignidade da pessoa humana e base elementar da Bioética. Para tanto, utilizou-se do método dedutivo e da pesquisa bibliográfica, partindo de premissas extraídas do conceito de dignidade do homem, autonomia, moral e ética, para buscar o reconhecimento do direito de morrer dignamente como decorrência do direito constitucional fundamental à vida.
\end{abstract}

Palavras-Chave: Direito de morrer com dignidade; Autonomia da vontade; Bioética; Dignidade da pessoa humana; Direito à vida digna.

\section{THE DIGNATIAL DEATH AS A FUNDAMENTAL RIGHT}

\begin{abstract}
The central theme of this paper addresses issues related to the need of preserving human dignity at life's terminality. It aims to present short considerations about the right to die with dignity under the grounds of will's autonomy as a strand of the principle of dignity of the human being and Bioethics elementary basis. Toward it, deductive method and bibliographical research have been employed, based on premises derived from the notion of human dignity, autonomy, morality and ethics, to claim recognition of the right to die with dignity as a consequence of fundamental constitutional right to life.
\end{abstract}

Keywords: Right to die with dignity; Autonomy of will; Bioethics; Human being dignity; Right to a dignified life.

\footnotetext{
${ }^{1}$ Mestranda em Ciência Jurídica pela Universidade Estadual Norte do Paraná - UENP. Participante do Grupo de pesquisa Políticas públicas e efetivação dos direitos sociais (UENP).

${ }^{2}$ Advogada. Mestranda em Ciência Jurídica pela Universidade Estadual Norte do Paraná - UENP. Participante do Grupo de pesquisa Eficácia dos Direitos Fundamentais no Brasil (UENP).
} 


\section{INTRODUÇÃO}

Aprioristicamente importa apresentar as razões, ainda que breves, da proposta do presente artigo de ressaltar à necessidade de se preservar a dignidade do homem na terminalidade da vida. E, para tanto, imprescindível à análise do direito a vida e do princípio da dignidade da pessoa humana trazidos pelo Estado Democrático de Direito a Constituição Federal de 1988.

$\mathrm{O}$ artigo relaciona os objetivos do direito à vida sendo interpretado de forma conjugada com a dignidade da pessoa humana, uma vez que o direito à vida só pode ser amplamente compreendido quando com dignidade, que em conjunto consistem nos princípios fundamentais da República federativa do Brasil, examinando a premente primordialidade de que a vida não deve ser entendida como somente sobrevivência com o mínimo possível para sua manutenção, mas deve ser interpretada no sentido de se possibilitar ao sujeito uma existência digna voltada à eficácia dos princípios constitucionais.

O estudo salienta os três fundamentais aspectos extraídos do conceito de dignidade humana, a saber: valor intrínseco, autonomia e valor social da pessoa humana.

Tomando-se como referência a dignidade humana no sentido de se converter no valor central que fundamenta toda a prática médica quando se traz à tona a reforma da prática jurídica e assistencial para um morrer com dignidade, houve a constatação de que a autonomia da vontade passou a assumir uma posição de destaque na análise crítica sobre o direito de morrer dignamente. E, é nessa perspectiva que a concepção de autonomia possui uma identificação tida como a existência de uma pessoa moral apta a se autodeterminar, fazer escolhas para a sua vida e realizá-las.

Feitas estas considerações, examinou-se que inexiste aparato judicial ou normativo específico que garanta expressamente o direito do ser humano de exercer sua autonomia de vontade de forma livre, manifestando-se pela recusa de tratamento, pelo desligamento de aparelhos ou, ainda, pela ingestão de medicamento letal. Contudo, demonstrou-se que no plano internacional, em que pese igualmente não exista um diploma, tratado ou norma que garanta expressamente o direito à morte digna, alguns países isoladamente já o reconheceram e o admitiram.

O método de abordagem empregado é o dedutivo que permite partir de premissas gerais para se chegar a uma conclusão específica sobre os modelos aqui confrontados. Serviu- 
se, no mais, do método dialético, com o objetivo de buscar possíveis sínteses para as divergências levantadas. Quanto ao procedimento, utiliza os métodos histórico, comparativo e sociológico, fazendo uso da interpretação sistemática. O tipo de pesquisa é o bibliográfico, a partir de livros e artigos científicos.

\section{DIREITO À VIDA E PRINCÍPIO DE DIGNIDADE DA PESSOA HUMANA}

Sabe-se que o caput do artigo $5^{\circ}$ da Constituição Federal protege a vida humana como um direito individual fundamental, que motiva e figura como decorrência lógica da garantia maior consubstanciada na dignidade da pessoa humana, há muito reconhecida em diversos diplomas internacionais, a exemplo da Declaração Universal dos Direitos do Homem (1948).

A dignidade humana, sob o olhar filosófico, constitui um valor, ligado ao ideal do que é bom, justo e virtuoso. Já no campo do Direito, sem deixar de ser um valor moral, ganha status de princípio jurídico, que justifica moralmente os direitos humanos e os direitos fundamentais, dentre os quais, o direito à vida, que nada mais é do que uma especificação da própria dignidade. De acordo com Sergio Rodrigo Martinez e Livia Gava Bersot (2015, p. 300) "o direito à vida pode ser relativizado por outros princípios a ele colidentes no caso concreto. Um deles é a dignidade da pessoa humana, que, assim como a vida, deve acompanhar toda a existência do sujeito, desde o nascimento até a morte".

A inserção da dignidade da pessoa humana como princípio previsto na Constituição Federal Brasileira adveio da onda de proteção instaurada em diversos países no pós Segunda Guerra, e deve ser apreciada como dispositivo capaz de garantir a efetiva aplicação das normas constitucionais que fundamentam o Estado Democrático de Direito.

Digno de nota é a conceituação de dignidade da pessoa humana trazida por Ingo Sarlet (2004, p. 59-60), segundo o qual se trata da:

qualidade intrínseca e distintiva reconhecida em cada ser humano que o faz merecedor do mesmo respeito e consideração por parte do Estado e da comunidade, implicando, neste sentido, um complexo de direitos e deveres fundamentais que assegurem a pessoa tanto contra todo e qualquer ato de cunho degradante e desumano, como venham a lhe garantir as condições existenciais mínimas para uma vida saudável, além de propiciar e promover 
sua participação ativa e corresponsável nos destinos da própria existência e da vida em comunhão com os demais seres humanos.

Valendo-se das lições acima, Carolina Gladyer Rabelo e Thais Castelli (2016, p. 169) destacam três importantes aspectos extraídos do conceito de dignidade humana, a saber, valor intrínseco, autonomia e valor social da pessoa humana. O primeiro, relativo ao plano ontológico, é aquele inerente a todos os seres humanos, que os distingue dos demais seres vivos. Segundo as autoras, o valor intrínseco da pessoa humana respalda inúmeros direitos fundamentais, sendo o primeiro deles, o direito à vida. Em torno deste direito estabelecem-se vários debates de enorme complexidade jurídica e moral, como os ligados à pena de morte, ao aborto e à morte digna.

Já a autonomia da vontade, elemento ético da dignidade humana que será melhor analisado adiante, liga-se à capacidade de autodeterminação individual, que engloba o direito de tomar as próprias decisões e desenvolver a personalidade da forma que melhor convier, realizando escolhas de forma livre, partindo de valorações morais próprias. Por fim, o valor comunitário, como aspecto social da dignidade, refere-se à inter-relação entre o indivíduo e o grupo a que pertence, que molda proteção do indivíduo contra atos do próprio sistema social em que está inserido. (RABELO; CASTELLI, 2016, p. 169).

Em razão dessa ampla acepção conferida ao conceito de dignidade da pessoa humana, consolidou-se o pensamento segundo o qual é estreita e interdependente a relação entre a dignidade e os direitos humanos e fundamentais, em que aquela figura como o sustentáculo basilar destes últimos, nos quais se observa a proteção do direito à vida digna.

Nesse sentido, Ingo Sarlet (2006, p. 115) destaca que:

Entendido como valor axiológico, o princípio fundamental da dignidade humana funciona como uma espécie de "lei geral" para os direitos fundamentais (digam-se direitos humanos positivados), que são, por sua vez, especificações da dignidade.

Como dito, ao se analisar o ordenamento jurídico interno, observa-se que a Constituição Federal faz menção expressa ao princípio da dignidade da pessoa humana logo em seu artigo $1^{\circ}$, inserindo-o como fundamento justificador do próprio Estado Democrático de Direito, garantindo-lhe, assim, fundamental importância. 
Por óbvio que a dignidade da pessoa humana está como fundamento essencial do Estado Democrático de Direito brasileiro que se perfaz pela efetivação dos vários direitos consagrados na Constituição, sendo que a "dignidade da pessoa humana é o fim supremo de todo o direito" (SILVA NETO, 2013, p. 252).

Elucida Guilherme Amorim Campos Silva (2007, p. 114) que a dignidade da pessoa humana "proclama o valor distinto da pessoa humana e tem, como consequência lógica, a afirmação de direitos específicos de cada ser humano, sem distinções de gênero, cor, credo, sexo e outras". Continua sua explicação (SILVA, 2007, p. 116):

Em síntese, definem o ser humano, na sua dignidade de pessoa, a igualdade, a liberdade, certos atributos como o direito fundamental à vida e outros (direito à intimidade, à honra, à própria imagem etc.) à subsistência em condições dignas. Encerra direito fundamental que põe a salvo o indivíduo contra qualquer violação por parte dos demais membros da coletividade e das instituições por eles controladas.

Mister salientar que, definir a nota de fundamentalidade em um direito exige relativo esforço. Isso porque os direitos fundamentais são pretensões que em cada momento histórico se descobrem a partir da perspectiva do valor da dignidade da pessoa humana (MENDES; COELHO; BRANCO, 2009, p. 271). Ademais, a tutela dos direitos fundamentais é ampla, dirigida tanto ao Estado, que deve respeitar os direitos de personalidade das pessoas que estão no seu território, como aos particulares, entre si, nas suas relações (SZANIAWSKI, 1993, p. 93).

Nesse contexto, a dignidade humana transforma-se no valor central que fundamenta toda a prática médica quando se traz à tona a reforma da prática jurídica e assistencial para um morrer com dignidade.

A busca se dá justamente pela proteção à dignidade, uma vez que ela não se perde mesmo estando a pessoa em condições de vulnerabilidade, fato este que elucida a ideia segundo a qual a dignidade acompanha toda a jornada da existência humana, incluindo o momento da morte (ARAUJO, 2011).

Dessa forma, a morte passa por uma ressignificação, desvencilhando-se do sentido biomédico relacionado a um fracasso técnico para incorporar a noção de se tratar um fato 
intrínseco da vida humana e, assim, merecedor de garantias e direitos. O direito de morrer dignamente, tal como o direito fundamental à vida digna, passa a incorporar a ideia de respeito à autonomia individual e a própria dignidade do ser em padecimento.

O direito à vida é entendido como direito natural positivado, e está alicerçado em conformidade ao processo histórico da sociedade, advindo através da compreensão adquirida no transcorrer da humanidade civilizada. No entanto, por consequência a este direito temos a proibição de ações - dimensão negativa do direito à vida -, que desrespeitem a existência e sobrevivência dos indivíduos.

Importante salientar que ao se falar em dimensão positiva do direito à vida é possível mobilizar a intervenção Estatal para a finalidade de preservação ao bem jurídico tutelado.

Com relação à eficácia positiva e negativa do direito à vida, Maria Helena Diniz (2007, p. 22) esclarece:

$\mathrm{O}$ art. $5^{\circ}$ da norma constitucional tem eficácia positiva e negativa. Positiva, por ter incidência imediata e ser intangível, ou não emendável, visto que não pode ser modificado por processo normal de emenda. Possui eficácia negativa por vedar qualquer lei que lhe seja contrastante, daí sua força vinculante, paralisante total e imediata, permanecendo intangível, ou não emendável pelo poder constituinte derivado, exceto por meio de revolução ou de ato de novo poder constituinte originário, criando e instaurando uma novel ordem jurídica.

Entende-se que o direito à vida, por ser norma constitucional impenetrável, possui preponderância sobre os demais direitos fundamentais existentes e positivados no Brasil. No caso de divergência entre respectivas normas, irá prevalecer aquela cujo princípio seja mais primordial. Conforme salienta Maria Helena Diniz (2007, p. 22) “A vida tem prioridade sobre todas as coisas, uma vez que a dinâmica do mundo nela se contém e sem ela nada terá sentido".

Claro e notório que a legislação Constitucional garante o direito à vida, todavia, essa proteção compreende ao direito de estar, permanecer e continuar vivo de uma maneira digna. Nos dizeres de Alexandre de Moraes (2007, p. 46-47) "a dignidade é um valor espiritual e moral inerente à pessoa, que se manifesta singularmente na autodeterminação consciente e responsável da própria vida". Além disso, "o direito à vida é o mais fundamental de todos os direitos, pois o seu asseguramento impõe-se, já que se constitui em pré-requisito à existência e exercício de todos os demais direitos". 
José Afonso da Silva (1999. p. 201) aduz que "De nada adiantaria a Constituição assegurar outros direitos fundamentais, como a igualdade, a intimidade, a liberdade, o bem estar, se não erigisse a vida humana num desses direitos". Vislumbra-se a vida humana como preceito essencial aos direitos fundamentais, considerado premissa da concepção de dignidade humana.

Compreender o direito à vida intrinsecamente relacionada à dignidade é o valor fundamental do texto constitucional, consoante expõe Paulo Hamilton Siqueira Jr. e Miguel Augusto Machado de Oliveira (2007, p. 19), para quem "Esse fato dota a vida humana de um valor fundamental e superior: dignidade da pessoa humana".

Inegável que o direito à vida, como uma das vertentes máximas do princípio da dignidade humana, possui ampla pertinência aos valores com os quais os seres humanos devem ser zelados.

Em sua conceituação, é certo asseverar que o direito à vida não privilegia unicamente a dimensão biológica da vida humana, mas reconhece e protege em igual medida a qualidade de vida do indivíduo, que está intrinsecamente ligado ao conceito de dignidade. Tanto é assim que a Constituição Federal brasileira insere como fundamentos do Estado Democrático de Direito a dignidade da pessoa humana e elenca o direito à vida como direito fundamental.

A morte ou o direito de morrer de forma digna pode ser visto como uma das facetas do direito à vida, que, como direito fundamental que é, incorpora em si a autonomia individual presente na dignidade do ser.

Nestes termos, possível concluir que inexiste antagonismo entre o direito à vida digna e o direito à morte digna. Trata-se, na realidade, de duas faces de uma mesma moeda, reconhecida, inclusive, pela Sagrada Congregação para a Doutrina da Fé, representativa da Igreja Católica, na Declaração da Eutanásia, segundo a qual:

Hoje é muito importante proteger, no momento da morte, a dignidade da pessoa humana e a concepção cristã da vida contra um «tecnicismo » que corre o perigo de se tornar abusivo. De facto, há quem fale de «direito à morte », expressão que não designa o direito de se dar ou mandar provocar a morte como se quiser, mas o direito de morrer com toda a serenidade, na dignidade humana e cristã.

No âmbito interno, o ordenamento jurídico brasileiro assegura o direito de viver no artigo $5^{\circ}$, caput, da Constituição, que descreve: “Todos são iguais perante a lei, sem distinção 
de qualquer natureza, garantindo-se aos brasileiros e aos estrangeiros residentes no País a inviolabilidade do direito à vida, à liberdade, à igualdade, [...]”.

Entretanto, apesar da Constituição não tratar expressamente sobre o direito de morrer com dignidade, parte da doutrina defende sua inclusão, ainda, que implícita, no direito à vida, pois, como vertente nascida do princípio da dignidade humana, o direito à vida digna abarca, tal como aquele, os três aspectos anteriormente mencionados, dentre os quais, a autonomia da vontade.

Nas lições de Carolina Gladyer Rabelo e Thais Castelli (2016, p. 174):

\begin{abstract}
A autonomia, elemento essencial da dignidade da pessoa humana é a chave nesse caso. Viver a vida com autonomia configura um direito potestativo, o que significa dizer que pode ser exercido sem a necessidade de autorizações alheias ao indivíduo. Afinal, nenhum ser humano prescinde de licença para viver a sua própria vida.
\end{abstract}

Assim, a morte que antes era objeto de exclusão e constituía em um verdadeiro tabu social transforma-se em tema de proliferação discursiva, é palco de debate moral, ético e político (MENEZES, 2009, pág.227).

Assim, ao ponderar o direito à vida, esta não deve ser compreendida como somente sobrevivência com o mínimo possível para sua manutenção, mas deve ser interpretada no sentido de se possibilitar ao sujeito uma vida digna em seu mais amplo aspecto, interpretação da qual decorre logicamente o direito de morrer com dignidade.

\title{
2. AUTONOMIA INDIVIDUAL: DO FUNDAMENTO BIOÉTICO AO DIREITO À MORTE COM DIGNIDADE
}

Recentemente, vive-se um processo crescente de afastamento do universo biomédico do tema relacionado à morte e, concomitantemente, sua aproximação de valores morais individualistas, fruto das noções liberais, notadamente da autonomia e do princípio da dignidade humana. Passou-se a se observar que a principal divergência em torno da antecipação da morte não é técnica e estanque, mas sim ética.

Nesse sentido, Débora Diniz e Sérgio Costa (2004, p. 127), elucidam que: 
Não é à toa que cresce a cada dia a discussão em torno da participação ativa dos profissionais da biomedicina na assistência à morte. Ao contrário do passado, em que decisões sobre o tratamento eram exclusivas da equipe de saúde, hoje, estimula-se que os usuários do sistema de saúde participem da tomada de decisões, especialmente daquelas consideradas centrais à existência humana, como as relacionadas ao início e ao fim da vida. O reconhecimento de que a decisão sobre o momento da morte não deveria ser apenas uma questão técnica, mas essencialmente de ordem ética e, portanto, da esfera privada das pessoas, vem sendo considerado um verdadeiro desafio aos profissionais de saúde. Tradicionalmente treinados para enfrentar e resistir à morte, sob a alegação de que a missão biomédica é a de salvar vidas, a resistência moral em torno de qualquer debate formal sobre a eutanásia ou mesmo o direito de morrer é ainda muito grande.

Nesse momento, a autonomia da vontade, como vertente principiológica da dignidade da pessoa humana, passou a assumir uma posição de destaque na análise crítica sobre o direito de morrer dignamente.

Ao se atrelar os conceitos de dignidade com o de autonomia, deve-se, primeiramente refletir na capacidade de autodeterminação do indivíduo, o direito que o mesmo possui em pronunciar o destino da respectiva vida e de avançar de maneira livre conforme a própria personalidade. Conceituam-se como a capacidade de vislumbrar as opções moralmente existentes e eleger quais deseja optar, mesmo que determinados caminhos possam acarretar em responsabilização.

Tom Beauchamp e James Childress foram, em 1978, os precursores dos ideais de respeito à autonomia como um mecanismo legítimo para a resolução dos conflitos morais em saúde. Em suas obras, por exemplo, "Principles of Biomedical Ethics", os autores mencionam não apenas a questão da autonomia em termos genéricos, mas enfatizam a importância do respeito à autonomia individual como uma peça-chave para a Bioética.

A partir de então, como dito, a doutrina vem caminhando no sentido de buscar uma espécie de autonomia do paciente, calcada fundamentalmente na dignidade da pessoa humana. Barroso (2013, p. 81) enfatiza que a autonomia é o elemento ético da dignidade humana, fundamento do livre arbítrio dos indivíduos, que lhes permite buscar o seu ideal de viver bem.

A autonomia da vontade constitui hoje, não apenas uma vertente da dignidade humana, mas também uma das pilastras que sustentam as teorias bioéticas vigentes, capazes de oferecer soluções a debates históricos travados na sociedade, que envolvem, quase sempre, divergências entre a comunidade médica, líderes religiosos, governos e opinião pública. 
Conforme salienta Álvaro Villaça de Azevedo (2010, p. 13), a autonomia e liberdade integram a dignidade. Desta maneira, podemos alegar que os direitos fundamentais possuem uma representação de dignidade, autonomia e consequente liberdade.

Nesse mesmo sentido, Maria Helena Diniz (2007) assevera que:

O ser humano é aquele que possui a liberdade, que tem a possibilidade de, ao menos teoricamente, determinar seu 'dever-ser'. É essa possibilidade que deve ser levada em conta, respeitada, considerada. A essência da dignidade do ser humano é o respeito mútuo a essa possibilidade de escolha. A especificidade do ser humano é a sua liberdade. A dignidade a ele inerente consistirá no respeito a essa possibilidade de escolha.

As decisões individuais podem ser consideradas autônomas não somente quando derivam de preferências individualizadas, mas também - e principalmente - quando resultam de processos informados e esclarecidos sobre tratamentos, terapêuticas, prognósticos, riscos, malefícios e benefícios de cada conduta biomédica. Isto é, para que uma decisão seja considerada autônoma não basta que a pessoa esteja livre de constrangimentos morais contrários a suas opiniões, mas também que se promova sua autonomia por meio da informação qualificada, transparente e compreensível (DINIZ; COSTA, 2004, p. 127).

Junte-se a isso o fato de que o próprio limite da autonomia individual está relacionado à dignidade da pessoa humana. A esse respeito, Sarlet (2012, p. 153) ressalva que há que levar em conta que este predomínio da perspectiva subjetiva encontra sua justificativa no valor outorgado à autonomia individual, na qualidade da dignidade da pessoa humana.

A proteção constitucional conferida à pessoa humana é no sentido de garantir a proteção do homem enquanto pessoa, o que fatalmente leva à questão dos limites do direito privado sobre a autonomia privada (FACHIN, 1998, p. 36).

Ao se analisar, assim, a concepção de autonomia, por ela se pode deduzir a existência de uma pessoa moral apta a se autodeterminar, fazer escolhas para a sua vida e realizá-las. Entende-se que o contrário desta liberdade individual viola a sua dignidade.

Conforme aduz Álvaro Villaça de Azevedo (2010, p. 24), a enfermidade do paciente, por mais grave que seja, não lhe retira o status de ser humano e, consequentemente, sua autonomia para agir com dignidade. 
Com relação à dignidade como autonomia no sistema constitucional brasileiro, Luís Roberto Barroso e Letícia Martel (2012, p. 28) verificam o cenário histórico de sua positivação, salientando:

[...] tendo como ponto de partida a Constituição, afigura-se fora de dúvida o predomínio da ideia de dignidade como autonomia. Dentro de uma perspectiva histórica, a Carta de 1988 representou uma ruptura com o modelo ditatorial intervencionista, constituindo o marco inicial da reconstrução democrática do Brasil. Daí a sua ênfase nas liberdades pessoais, parte essencial de um longo elenco de direitos individuais e garantias procedimentais.

Para Barroso e Martel (2012, p. 18), a dignidade como autonomia "é a visão que serve de fundamento e justificação para os direitos humanos e fundamentais." Reputa-se que preservar à autonomia individual de uma pessoa é o que promove a sua vicência humana digna, e, desta forma, concede recursos que propiciam a tomada de decisões e atitudes com a finalidade de auferir propósitos de vida traçados.

Através desta perspectiva Ingo Sarlet (2009, p. 30) esclarece que contempla na "autonomia e na autodeterminação uma das dimensões da dignidade, na medida em que fornecem condições de o indivíduo tomar decisões sobre os aspectos mais relevantes de sua existência".

Desse modo, não há como negar que a autonomia individual possui evidente amparo jurídico-constitucional, pois delineado mediante dispositivos que asseguram a dignidade da pessoa humana.

É sob essa perspectiva que se deve analisar e compreender a temática que aborda o direito de morrer dignamente, como um direito fundamental que integra a base principiológica da dignidade da pessoa humana, posto que, ao fim e ao cabo, trata-se de um viés interpretativo que decorre logicamente do proprio direito à vida digna, à liberdade individual e a autonomia de vontade. Em outras palavras, há evidente proteção ao direito a uma morte digna, assim compreendida como uma morte sem sofrimento e de acordo com a vontade consciente e esclarecida do indivíduo titular de direitos.

A implementação de uma filosofia mais condescendente aplicável à pacientes em estágios terminais torna-se uma alternativa benéfica no sentido de se criar uma cultura de 
respeito à dignidade do ser humano quando do enfrentamento da morte, que, tal como a vida, igualmente corresponde a um direito humano.

Mas, para que os métodos de encurtamento da vida pela antecipação da morte por meios dignos sejam considerados como uma possibilidade na assistência em saúde, imperioso que o respeito à autonomia individual, aclarada e informada, seja promovido e garantido. A ideologia do vitalismo, muito defendida pela comunidade médica, deve ser seriamente combatida, pois a desconsideração da vontade do doente terminal, que expressamente se manifestou de forma contrária ao tratamento médico indicado para postergação da morte, implica diretamente na violação de direitos e liberdades individuais e, em última instância, no atentado à dignidade humana.

Assim, a doutrina do consentimento impera quando está em jogo o poder de decisão conferido ao paciente, que aceita ou recusa a realização de um tratamento ou que opta por outros meios de encurtamento da vida. O paciente necessariamente deve compreender o seu estado de saúde e as possibilidades de intervenções que existem, bem como as eventuais consequências de cada uma delas.

É certo que o tema ainda hoje carece de regulamentação jurídica, de modo que não se pode falar na plena licitude das formas de antecipação da morte, justamente por vivermos em um Estado de Direito, em que há predominância e prevalência do Direito como norma social.

Apesar disso, é importante observar e levar em consideração que o tema central referente ao direito de morrer com dignidade tem raízes significativas no campo da antropologia social, da ética e da moral, merecendo ser analisado sob tais prismas, a par da clara necessidade de positivação legal.

A decisão pela antecipação da morte, para fazer cessar o sofrimento do findar da vida, deve partir, assim, de dois princípios éticos que devem guiar não apenas a prática profissional do corpo médico, mas também a compreensão de inúmeros conflitos de ordem moral: os princípios do respeito à autonomia e à dignidade. 


\section{DIREITO DE MORRER OU DEVER DE PERMANECER VIVO? O PROLONGAMENTO DA VIDA (IN)DIGNA}

Em que pese no Brasil o debate sobre as formas de antecipação da morte e direito a uma morte digna ainda seja incipiente quando comparado a outros países, este é um assunto que ganha cada dia mais destaque, como um dos temas prioritários da Bioética, da afirmação da autonomia da vontade e, em última análise, da garantia da dignidade da pessoa humana.

Sabe-se que o Brasil, como Estado Democrático de Direito, tem o dever constitucional de preservar a vida das pessoas que aqui estejam. E mais que isso. Cumpre ao Estado cuidar para que a população exerça a plenitude da vida com o máximo de dignidade. Contudo, questiona-se se essa intervenção estatal deve existir mesmo nos casos em que a pessoa em estágio terminal deseja morrer de forma digna.

De acordo com Melina Chagas Barroso (2014, p. 39), um dos principais elementos da 'preservação da vida' pelo Estado é manter o valor da vida humana. Ocorre que diversos precedentes jurisprudenciais enunciam a relatividade desse valor, notadamente quando a necessidade de tratamento médico está envolvida, enunciando que o valor da vida diminui não por uma decisão de recusar tratamento, mas pela impossibilidade de garantir ao indivíduo o direito de escolha.

Como visto anteriormente, o valor da vida humana e, por consequência, do direito à vida digna, possui diversas dimensões, dentre as quais certamente se encontra o poder de escolha, que reflete diretamente a autodeterminação do indivíduo.

A renúncia do direito à vida apenas pode ser exercida pelo próprio titular, de modo que a escolha pela morte reveste-se do mesmo caráter de direito conferido à vida. É nesse sentido, inclusive, o posicionamento defendido por Carolina Gladyer Rabelo e Thais Castelli (2016, p. 174):

Afinal, se não se tratasse de direito, seria, mormente, conhecido como "dever de viver". O que não é o caso. Tal "dever de viver" geraria um rol extensivo de consequências jurídicas, iniciado pela punição da tentativa de suicídio, pela proibição dos esportes radicais e qualquer outra atividade que ofereça riscos de morte em geral. 
A ideia levada ao extremo e defendida por parte da doutrina implica em reconhecer que não garantir o direito de morrer com dignidade configura verdadeiro constrangimento ilegal, podendo inclusive culminar em abuso de poder e lesão corporal. Nestes termos, ensina Claus Roxin (2005, p. 23):

se o paciente recusa a operação que salvaria sua vida, ou a necessária internação numa unidade de tratamento intensivo, deve o médico abster-se de tais medidas e, se for o caso, deixá-lo morrer. Esta solução é deduzida, corretamente, da autonomia da personalidade do paciente, que pode decidir a respeito do alcance e da duração de seu tratamento.

A lógica ora aplicada é nítida, já que se assim não o fosse, se um paciente em estágio terminal de uma determinada doença recusasse tratamento considerado vital para o prologamento de sua vida, sua recusa o faria incidir em algum crime, já que estaria atentando contra o seu direito de viver. Não seria caso de direito à vida, mas sim de dever.

Contudo, como prova da existência ao menos implícita do direito à morte digna no ordenamento pátrio, é o fato de não ser esta a consequência jurídica para aquele que, por exemplo, recusa tratamento médico, vez que inexiste o tipo penal ligado à hipótese elaborada.

A Constituição Federal Brasileira é clara ao garantir, em seus artigos $1^{\circ}$, III e $5^{\circ}$, III a dignidade da pessoa humana como fundamento do Estado Democrático de Direito. Apesar disso, ainda hoje inexiste aparato judicial ou normativo específico que garanta expressamente o direito do ser humano de exercer sua autonomia de vontade de forma livre, manifestando-se pela recusa de tratamento, pelo desligamento de aparelhos ou, ainda, pela ingestão de medicamento letal.

No plano internacional, em que pese igualmente não exista um diploma, tratado ou norma que garanta expressamente o direito à morte digna, alguns países isoladamente já o reconheceram e o admitiram. É o caso, por exemplo, da Holanda, que regulamentou através de ato legislativo o término da vida por médico a pedido do paciente, em 2002. A eutanásia, neste caso, mesmo sofrendo forte controle no país, também é admitida.

Do mesmo modo, a legalização de formas de antecipação da morte, como a eutanásia, ocorreu em 2002 na Bélgica, após manifestação favorável do Comitê Consultivo Nacional de Bioética, que autoriza a prática em pacientes de qualquer idade, desde que portem doença que esteja em fase avançada ou terminal. (RABELO; CASTELLI, 2016, p. 177). 
Ainda, tanto Suíça, quanto o Uruguai e a Colômbia, apesar de não terem regulamentação normativa expresssa, reconhecem o direito de morrer com dignidade e toleram as práticas de encurtamento da vida conforme a gravidade da doença.

Nessa perspectiva, destaca Melina Chagas Barroso (2014, p. 45) que:

O suicídio medicamente assistido é legal na Holanda, Bélgica, Suíça e Luxemburgo. Exceto para a Suíça, as leis limitam o procedimento apenas para os residentes e sob condições estritas. A Suíça só permite a vinda de estrangeiros para a morte assistida, desde que seja autruísta, não tenha fins lucrativos ou de dolo.

Ademais, países como Portugal e Alemanha, cujos sistemas jurídicos são paradigmas para o Brasil, tipificam como crime o homicídio, tal como o ordenamento pátrio. Mas, além deste, possuem um crime denominado "homicídio a pedido da vítima", em que se aplica uma pena meramente simbólica, o que demonstra ao menos complacência com as formas de antecipação da morte. (RABELO; CASTELLI, 2016, p. 177).

Assim, o que se observa é que há hoje uma tendência global de mudança para a aceitação do direito à morte digna como fragmento do direito à vida. A dignidade humana, nesse contexto, transforma-se no valor central que fundamenta a prática médica, trazendo a importância de sua preservação durante toda a jornada da existência do homem, incluindo aí o momento da morte.

A morte vem passando, dessa forma, por uma ressignificação, libertando-se da ideia de fracasso técnico para mostrar-se como um fato intrínseco da vida humana. Essa transformação traz a possibilidade de abordar o tema morte como intrinsecamente ligado ao respeito da autonomia e liberdade individual, da privacidade e do direito de morrer dignamente. Assim, a morte que antes era objeto de exclusão e constituía em um verdadeiro tabu social transforma-se em tema de proliferação discursiva, é palco de debate moral, ético e político (MENEZES, 2009, p. 227).

A morte digna, dessa forma, tanto quanto a vida digna, compreende um direito humano. E, por morte digna entenda-se o ideal de uma morte sem dor, sem angústia e de acordo com a vontade do indivíduo titular do direito de viver e de morrer.

Conforme brilhantemente assevera Ronald Dworkin (2003, p. 208), 
A morte domina porque não é apenas o começo do nada, mas o fim de tudo, e o modo como pensamos e falamos sobre a morte - a ênfase que colocamos no "morrer com dignidade" - mostra como é importante que a vida termine apropriadamente, que a morte seja um reflexo do modo como desejamos ter vivido.

Desse conceito extrai-se a ideia da boa morte, segundo a qual é inevitável que cada vida humana um dia chegue ao fim, isto é, que morrer é consequência lógica da própria vida, de modo que é importante assegurar que esse processo ocorra de uma forma digna, cuidadosa e menos dolorosa possível.

No Brasil, como anteriormente citado, elegeu-se a vida como bem maior merecedor de proteção, acabando por criminalizar qualquer ato, prática ou mecanismo que leve à exclusão, até mesmo, da sobrevida inviável. E apesar de inexistir instrumento normativo que regulamente a proteção à morte digna, possível encontrar dispositivos esparsos que proíbem algumas formas de encurtamento da vida.

Ao menos em relação à eutanásia, o Direito Penal brasileiro a considera equivalente ao crime de homicídio, ainda que privilegiado, conforme disposição do artigo 121, segundo o qual "matar alguém: pena de reclusão, de seis a vinte anos", e do artigo $121 \S 1^{\circ}$ do Código Penal “[...] se o agente comete crime impelido por motivo de relevante valor social ou moral, ou sob o domínio de violenta emoção, logo seguida a injusta provocação da vítima, o Juiz pode reduzir a pena de um sexto a um terço [...]”. (BRASIL, 2013).

Ocorre que, inobstante os dispositivos legais que proíbem certas formas de antecipação da morte em defesa do incontestável direito à vida, fato é que a sua proteção se fragiliza a partir das diversas concepções de vida boa, que inclui a sua dignificação no início, meio e no seu fim, isto é, no processo de morte.

Nesse sentido, se por um lado o Estado tem o dever de proporcionar saúde às pessoas para que estas gozem de uma vida digna, por outro, não pode obrigar o indivíduo a adotar conduta não prevista em lei, de modo que não é possível impor tratamento ao paciente, sem antes consultá-lo. Dessa forma, um verdadeiro contraponto aos ideais de proteção ao direito à vida, insculpidos no Código Penal, que demonstram nao se tratar de direito absoluto, encontra-se, dentre outros dispositivos, no artigo 15 do Código Civil, por meio do qual se consagrou princípio da liberdade de escolha do indivíduo, que tem a faculdade de recusar certos tratamentos médicos, ao dispor que "Ninguém pode ser constrangido a submeter-se, com risco de vida, a tratamento médico ou a intervenção cirúrgica”. 
Além do código civilista, o Código de Ética Médica, em seu Capítulo I, inciso VI, dispõe que "O médico guardará absoluto respeito pelo ser humano e atuará sempre em seu benefício. Jamais utilizará seus conhecimentos para causar sofrimento físico ou moral, para o extermínio do ser humano ou para permitir e acobertar tentativa contra sua dignidade e integridade". Ainda, o inciso XXI do mesmo Capítulo assevera que "No processo de tomada de decisões profissionais, de acordo com seus ditames de consciência e as previsões legais, o médico aceitará as escolhas de seus pacientes, relativas aos procedimentos diagnósticos e terapêuticos por eles expressos, desde que adequadas ao caso e cientificamente reconhecidas.".

Corroborando com o poder de decisão do paciente, como corolário do direito de liberdade, o mesmo Código de Ética Médica destaca, agora em seu Capítulo IV, que trata "Dos Direitos Humanos", que é vedado ao médico "Deixar de garantir ao paciente o exercício do direito de decidir livremente sobre sua pessoa ou seu bem-estar, bem como exercer sua autoridade para limitá-lo.”.

Assim, possível concluir que, apesar de perdurarem ainda hoje proibições quanto a certos modos de encurtamento da vida, a exemplo da eutanásia, e mesmo ciente de que não existe na atualidade um diploma nacional ou internacinal que garanta expressamente o direito de escolha do paciente sobre a forma de encerramento de sua vida, fato é que a proteção constitucional conferida à dignidade humana e à liberdade do indivíduo, que pode fazer tudo aquilo que não lhe seja proibido, influem diretamente para a prevalência da autonomia em prol do direito de morrer dignamente.

De acordo com os ensinamentos de Horta,

quando a vida física é considerada o bem supremo e absoluto, acima da liberdade e da dignidade, o amor natural pela vida se transforma em idolatria"; "a medicina promove implicitamente esse culto idólatra da vida, organizando a fase terminal como uma luta a todo custo contra a morte"; e, por isso, há "centenas ou talvez milhares de doentes hoje jogados a um sofrimento sem perspectiva em hospitais, sobretudo em UTIs e emergências", os quais, "não raramente, acham-se submetidos a uma parafernália tecnológica que não só não consegue minorar-lhes a dor e o sofrer, como ainda os prolonga e os acrescenta inutilmente.

Sobre o princípio da liberdade, inclusive, há de se ressaltar que a concepção de autonomia está estritamente ligada à liberdade. A capacidade da escolha depende diretamente 
da liberdade para escolher, de modo que o indivíduo autônomo é considerado como um sujeito livre para escolher a sua própria vida e, por consequência, sua própria morte. $\mathrm{O}$ princípio e garantia à liberdade consigura-se, assim, como um dos pilares da dignidade do homem, visto que lhe garante o poder exercer todos os demais direitos e sua censura constitui clara violação constitucional.

Relativamente ao direito de morrer, o respeito à autonomia e, por via lógica, à liberdade, torna a morte uma extensão da vida, em que o sujeito é ativo no seu processo de escolha, individualizando-o de acordo com suas preferências, crenças e valores.

Frise-se que a proposta ora considerada não implica em apressar indeterminada e indiscriminadamente o findar da vida, mas humanizar a chegada da morte e o direito de escolha do indivídio à luz da garantia consagrada pela própria Constituição Federal de 1988, que trouxe a possibilidade de discussão sobre o direito de morrer dignamente quando fundamentou o Estado Democrático de Direito no princípio da dignidade da pessoa humana.

O direito de morrer é assim um corolário do direito à vida, que, apesar de toda proteção conferida pelo ordenamento jurídico pátrio, não deve transmudar-se em dever de viver.

Morrer dignamente não significa, portanto, a realização de intervenções que causam a morte. Ao revés, defender o direito de morrer dignamente é reconhecer a liberdade do paciente e de sua autodeterminação, em prol da garantia da dignidade humana.

O direito de morrer de forma digna é a reivindicação com base na dignidade da pessoa, sua liberdade, autonomia, consciência e direitos de personalidade de ter uma morte natural, humanizada, sem o prolongado sofrimento decorrente de tratamento inútil. É, assim, escolher o local onde passar os últimos momentos, junto da pessoa de sua escolha, por opção afetiva. É morrer sem dor, com conforto espiritual, se for essa a vontade do paciente. (ARAÚJO, 2011, p. 152-153).

Segundo ensina Maria de Fátima Freire de Sá (2001, p. 60):

[...] o ser humano tem outras dimensões que não somente a biológica, de forma que aceitar o critério da qualidade de vida significa estar a serviço não só da vida, mas também da pessoa. O prolongamento da vida somente pode ser justificado se oferecer às pessoas algum benefício, ainda assim, se esse benefício não ferir a dignidade do viver e do morrer [...]. 
Há que se relembrar que, quando um indivíduo diz que quer morrer, na realidade está dizendo que quer viver de outra forma.

Desses pressupostos extrai-se a proposição de que o Estado não deve olvidar esforços para garantir ao ser humano uma vida digna. Contudo, pautando-se nestes ideais, deve assegurar a mesma dignidade no momento da morte, uma vez que morrer dignamente é direito que, tal como viver dignamente, integra as premissas fundamentais do ser humano.

Ainda, no contexto da boa morte, o morrer torna-se uma questão de deliberação pessoal sobre o momento e principalmente sobre a forma da morte como um exercício da autonomia individual e da liberdade, intrínsecas ao ser humano.

Assim, trazendo à evidência e ao centro da discussão a importância conferida a vontade expressa e consciente do paciente, como exercício do seu direito de liberdade e dignidade, deve-se reconhecer a morte como elemento e desdobramento inevitável da vida humana, garantindo ao indivíduo o poder de escolha, como último suspiro na garantia e efetivação de sua dignidade.

\section{CONSIDERAÇÕES FINAIS}

Tamanha importância possui para o homem o direito à vida, sendo garantido pela Constituição Federal. Fato é que o direito de morrer dignamente, tal como o direito fundamental à vida digna, passa a incorporar a ideia de respeito à autonomia individual e a própria dignidade do ser em padecimento.

A morte ou o direito de morrer de forma digna pode ser visto como uma das facetas do direito à vida, que, como direito fundamental que é, incorpora em si a autonomia individual presente na dignidade do ser.

Trata de um assunto que envolve as relações jurídicas e sociais, que necessita para tanto da compreensão de dois princípios éticos que devem guiar não apenas a prática profissional do corpo médico, mas também a compreensão de inúmeros conflitos de ordem moral: os princípios do respeito à autonomia e à dignidade, bem como, suas e correlações aplicadas ao direito à vida.

Diante de tão elevada proteção à vida, o direito de morrer, o respeito à autonomia e, por via lógica, à liberdade, torna a morte uma extensão da vida, em que o sujeito é ativo no 
seu processo de escolha, individualizando-o de acordo com suas preferências, crenças e valores, deixando de ser refém das ciências médicas e da tecnologia, as quais buscam cada vez mais procrastinar o final da existência de uma pessoa, muitas vezes sem levar em consideração o desejo desta.

Ficou evidente, ainda, que a morte passa por uma ressignificação, desvencilhando-se do sentido biomédico relacionado a um fracasso técnico para incorporar a noção de se tratar um fato intrínseco da vida humana e, assim, merecedor de garantias e direitos.

Ademais, ao se vincular os conceitos de dignidade com o de autonomia, deve-se, primeiramente refletir na capacidade de autodeterminação do indivíduo, o direito que o mesmo possui em pronunciar o destino da respectiva vida e de avançar de maneira livre conforme a própria personalidade. Conceituam-se como a capacidade de vislumbrar as opções moralmente existentes e eleger quais deseja optar, mesmo que determinados caminhos possam acarretar em responsabilização.

Importante ressaltar que defender o direito de morrer dignamente é reconhecer a liberdade do paciente e de sua autodeterminação, em prol da garantia da dignidade humana.

Assim, possível concluir que, apesar de perdurarem ainda hoje proibições quanto a certos modos de encurtamento da vida, a exemplo da eutanásia, e mesmo ciente de que não existe na atualidade um diploma nacional ou internacional que garanta expressamente o direito de escolha do paciente sobre a forma de encerramento de sua vida, fato é que a proteção constitucional conferida à dignidade humana e à liberdade do indivíduo, que pode fazer tudo aquilo que não lhe seja proibido, influem diretamente para a prevalência da autonomia em prol do direito de morrer dignamente.

\section{REFERÊNCIAS}

ARAÚJO, Armando Otávio Vilar de. Múltiplos enfoques sobre a morte e do morrer. In R. D. Moritz, Conflitos Bioéticos do Viver e do Morrer (pp. 141-156). Brasília: Conselho Federal de Medicina - CFM; 2011. p. 141-155. Rachel Duarte Moritz Organizadora. Disponível em: <http://portal.cfm.org.br/images/stories/biblioteca/conflitos.pdf >. Acesso em 29 ago. 2018.

\section{ASSEMBLEIA GERAL DAS NAÇÕES UNIDAS. Declaração Universal dos Direitos} Humanos. Paris, 1948.

AZEVEDO, Álvaro Villaça. Parecer Jurídico Autonomia do paciente e Direito de Escolha de Tratamento médico sem transfusão de sangue mediante o novo código de ética médica- resolução CFM 1931/09. São Paulo 8 de Fevereiro de 2010. 
BARROSO, Luís Roberto. A dignidade da pessoa humana no direito constitucional contemporâneo: a construção de um conceito jurídico à luz da jurisprudência mundial. Belo horizonte: Editora Fórum, 2013.

BARROSO, Luis Roberto; MARTEL, Letícia de Campos Velho. A morte como ela é: dignidade e autonomia individual no final da vida. In: GOZZO, Débora; LIGIERA, Wilson Ricardo. Bioética e Direitos Fundamentais (Orgs.). São Paulo: Saraiva, 2012.

BARROSO, Melina Chagas. Direito à morte: Autonomia para morrer com dignidade. 2014. 77 f. TCC (Graduação) - Curso de Direito, Ciências Jurídicas e Sociais, Universidade de São Paulo. Faculdade de Direito de Ribeirão Preto, Ribeirão Preto, 2014.

Card. SEPER, Franjo; Fr. HAMER, Jerónimo. Declaração Sobre a Eutanásia. Sagrada Congregação para a Doutrina da Fé. Cidade do Vaticano, 1980. Disponível em: <www.vatican.va/roman_curia/congregations/cfaith/documents/rc_con_cfaith_doc_19800505 _euthanasia_po.html>. Acesso em: 26 ago. 2018.

COSTA, Helena Regina Lobo da. A dignidade humana: teorias de prevenção geral positiva. São Paulo: Revista dos Tribunais, 2008.

DINIZ, Débora; COSTA, Sérgio. Morrer com dignidade um direito fundamental. In Camarano, Os Novos Idosos Brasileiros: muito além dos 60. 2004. p. 121-134. Rio de Janeiro: Instituto de Pesquisa Econômica Aplicada (Ipea). Disponível em: <http://www.ipea.gov.br/agencia/images/stories/PDFs/livros/Arq_10_Cap_04.pdf>. Acesso em 27 ago. 2018.

DINIZ, Maria Helena. O estado atual do biodireito. 4 ed. São Paulo: Saraiva, 2007.

DWORKIN, Ronald. Domínio da vida: Aborto, eutanásia e liberdades individuais. São Paulo: Martins Fontes, 2003.

FACHIN, Luiz Edson. Repensando Fundamentos do Direito Civil Brasileiro contemporâneo. Rio de Janeiro: Renovar, 1998.

FREIRE JÚNIOR, Aluer Baptista; AMIGO, Andréia Vieira. O Direito de Morrer com Dignidade. Revista Educação, Meio Ambiente e Saúde - UFSC, Santa Catarina, v. 7, n. 1, p.40-61, 2017. Trimestral. Disponível em: <http://www.egov.ufsc.br/portal/sites/default/files/130-358-1-pb.pdf>. Acesso em: 04 set. 2018.

HORTA MP. Paciente crônico - paciente terminal - eutanásia: problemas éticos da morte e do morrer. In: ASSAD, J. E. (Coord.). Desafios éticos. Brasília: Conselho Federal de Medicina, 1993. p. 219-28.

MARTINEZ, Sergio. BERSOT, Livia. Análise crítica da proibição do suicídio assistido no Brasil. Argumenta Journal Law, Jacarezinho - PR, Brasil, n. 23. p. 283-311. Disponível em: 
< http://seer.uenp.edu.br/index.php/argumenta/article/view/593/pdf_106>. Acesso em: 06 set. 2018.

MENDES, Gilmar Ferreira; COELHO, Inocêncio Mártires; BRANCO, Paulo Gustavo Gonet. Curso de direito constitucional. 4. ed. São Paulo: Saraiva, 2009.

MENEZES, Rachel Aisengart. Reflexões em torno da Morte e o Morrer. In F. S. Santos, A Arte de Morrer - Visões Plurais Volume 2. 2009. (pp. 227-236). São Paulo: Comenius

MORAES, Alexandre de. Direitos humanos fundamentais. São Paulo: editora Atlas, 2007.

RABELO, Carolina Gladyer; CASTELLI, Thais. Direito de morrer com dignidade: proteção à luz do direito internacional e nacional. Revista Interdisciplinar de Direitos Humanos, Bauru-SP, v. 4, n. 2, p.161-182, 2016. Semestral. Jul. a dez. 2016. Disponível em: <http://www2.faac.unesp.br/ridh/index.php/ridh/article/view/395>. Acesso em: 26 ago. 2018.

ROXIN, Claus. A tutela penal da vida humana. São Paulo: Ed. Damásio de Jesus, 2005.

SÁ, Maria de Fátima Freire de. Direito de Morrer. Belo Horizonte: Del Rey, 2001.

SARLET, Ingo Wolfgang. Dignidade da pessoa humana e direitos fundamentais na Constituição Federal de 1988. 9.ed. rev. atual. Porto Alegre: Livraria do Advogado editorial, 2012.

SARLET, Ingo Wolfgang. Dimensões da dignidade. Porto Alegre: Livraria do Advogado, 2009.

SILVA, Guilherme Amorim Campos. Dicionário Brasileiro de Direito Constitucional. São Paulo: Saraiva, 2007.

SILVA, José Afonso da. Curso de direito constitucional positivo. 16. ed. São Paulo: Malheiros, 1999.

SILVA NETO, Manoel Jorge e. Curso de Direito Constitucional. 8. Ed., Rio de Janeiro: Saraiva, 2013.

SIQUEIRA JR., Paulo Hamilton; OLIVEIRA, Miguel Augusto Machado de. Direitos humanos e cidadania. São Paulo: Revista dos Tribunais, 2007.

SZANIAWSKI, Elimar. Direitos da Personalidade e sua tutela. São Paulo: Revista dos Tribunais, 1993.

TUBAU, Joan Mir; ALIBÉS, Ester Busquets. Principios de Ética Biomédica,Tom L. Beauchamp y James F. Childress. Tribuna Abierta del Institut Borja de Bioètica, Universitat Ramon Llull, Barcelona, Espanha. v. 17, n. 64, p.1-7, 2011. Semestral. Setembro a dezembro de

2011.

Disponível em: 
<http://www.ucv.ve/fileadmin/user_upload/facultad_agronomia/Producion_Animal/Producci On_Animal/Bioetica.pdf>. Acesso em: 28 ago. 2018.

VALADIER, Paul. A pessoa em sua dignidade. In: Concilium - Revista Internacional de Teologia, 2003. 